\title{
Da canção ao livro: procedimentos de transposição e referência em Gigolô de Bibelôs, de Waly Salomão
}

\author{
Augustto Corrêa Cipriani ${ }^{\mathrm{i}}$
}

\section{RESUMO}

Considerando o papel formador da canção popular na poética de Waly Salomão, este artigo analisa as operações intermidiáticas de transposição e referência em Gigolô de Bibelôs, de 1983. Para tanto, toma-se como base a seção dedicada às letras de música nesse volume, com ênfase nos procedimentos de transposição da canção para a mídia verbal escrita. Em seguida, ressaltam-se intertextualidades com a canção popular brasileira, tanto em sua poesia quanto em suas letras de música. Desse modo, demonstra-se a centralidade da canção e os jogos poéticos e editoriais de que Salomão lança mão para aproximar canção popular e poesia.

Palavras-chave: Canção popular; Letra de música; Transposição; Referência; Waly Salomão.

\begin{abstract}
Considering the formative role of popular song in Waly Salomão's poetics, in this paper we analyze the intermedia operations of transposition and reference in Gigolo de Bibelôs, from 1983. For such purpose, we take as our starting point the section dedicated to the lyrics in the book, with an emphasis on the transposition procedures from song to written verbal media. Next, we highlight the intertextualities with Brazilian popular song, both in Salomão's poetry as well as in his lyrics. This demonstrates both the centrality of the song and the poetic and editorial tricks Salomão uses to bring popular song and poetry together.
\end{abstract}

Keywords: Popular song; Lyrics; Transposition; Reference; Waly Salomão.

Waly Salomão foi um artista polivalente, sendo reconhecido tanto por sua obra poética como pelas letras de música que compôs em parceria com grandes nomes da Música Popular Brasileira. ${ }^{1}$ Nesse sentido, tendo em vista a carreira do poeta de Jequié, o livro Gigolô de Bibelôs coloca-se em um lugar de destaque: publicado em 1983, mais

\footnotetext{
${ }^{\text {i }}$ Doutorando em Estudos Literários na UFMG, área de Teoria da Literatura e Literatura Comparada, linha de pesquisa Literatura e Políticas do Contemporâneo. augusttocipriani@gmail.com
} 
de uma década após seu livro de estreia Me segura qu'eu vou dar um troço, trata-se de uma publicação com caráter de coletânea, reunindo boa parte de sua produção até o momento. Nele se reproduz seu primeiro livro na íntegra, que havia sido lançado em 1972 em tiragem reduzida, além de diferentes seções que abarcam várias facetas de sua poética. A última dessas, Uma dúzia e meia de canções e mais uma de quebra, por sua vez, reproduz letras de música por ele compostas, acompanhadas de jogos tipográficos, notas e intervenções visuais. Desse modo, este artigo se volta às letras de música presentes em Gigolô de Bibelôs, buscando compreender tanto os modos com que se deu a transposição da canção ao livro, quanto os efeitos que a presença da letra de música no livro traz para a escrita de Waly.

Cabe, primeiramente, salientar que Waly Salomão se dedicou, no meio musical, quase que exclusivamente à composição de letras de música. Desse modo, seu trabalho na canção levanta duas questões significativas para a análise: Waly encarna o papel de letrista, importante função na canção popular nacional; e suas composições são coletivas, contando com a participação de algum músico como coautor. O início da produção das letras de música de Waly Salomão se dá num momento de consolidação da figura do letrista na Música Popular Brasileira (MPB). Como aponta Ana Maria Bahiana, foi a partir das composições de letras de Vinicius de Moraes que o papel do letrista passa a se consolidar no Brasil - apesar de a autora apontar outros importantes letristas no cancioneiro nacional desde o século XIX, foi Vinicius que possibilitou a formação de uma tradição (BAHIANA, 1980, p. 183-184). Waly Salomão é ciente do papel do poeta carioca como marco histórico do papel do letrista, afirmando o seguinte: "Somos nós letristas de música popular brasileira, participantes de um bloco - um afoxé, uma escola de samba, uma banda de rock ou de reggae ou de funk - intitulado não Filhos de Gandhi, mas FILHOS DE VINICIUS DE MORAIS" (SALOMÃO, 2005, p. 122-123). Posteriormente às parcerias de Vinicius de Moraes que compõem os grandes clássicos da Bossa Nova, a Tropicália foi um segundo momento de efervescência do papel do letrista, em especial o trabalho de Capinam - que escreveu a letra de Miserere Nobis, musicada por Gilberto Gil - e Torquato Neto - que compôs Geleia Geral, também com Gil.

Waly Salomão se situa no conjunto de letristas que compuseram nos anos 1970 e 1980 aquilo que Bahiana caracteriza como consolidadores da "função letrista" no 
cenário nacional (BAHIANA, 1980, p. 183). Quase a totalidade dos letristas que compõem essa geração - assim como seus antecessores Vinicius de Moraes e Torquato Neto - também atuavam no campo da poesia, publicando livros e coletâneas de poemas, o que indica a óbvia convergência entre letra de música e poesia. Assim, se por um lado, é possível estabelecer relações entre poesia e canção no cenário cultural nacional, por outro lado, Nelson Barros da Costa, em sua tese, busca tratar das diferenças entre esses dois gêneros discursivos, apontando o processo de "anexação excludente", que consiste na transferência da letra de música para o campo da poesia, ao mesmo tempo que a situa enquanto uma forma menos prestigiosa de poesia (COSTA, 2001, p. 377-379). Ou seja, a letra de música é muitas vezes compreendida como uma poesia menor, o que explica por que notórios letristas são considerados "poetas", tanto pelo público quanto pela crítica - como se, ao criar uma letra de música de qualidade estética superior, seria possível "elevá-la" ao mesmo patamar da poesia.

Em Gigolô de Bibelôs, Waly Salomão dedica uma seção - Uma dúzia e meia de canções e mais uma de quebra - para a publicação de suas letras de música, com algumas anotações técnicas e pessoais, elencando as parcerias nas composições e expondo alguns apontamentos sobre as canções. Tal atitude parece corroborar a teoria da "anexação excludente" de Costa: se por um lado, Waly escolheu trazer para seu livro as letras de música; por outro, preferiu separá-las do restante do livro, indicando sua diferença com relação aos poemas. Existe, no entanto, um trabalho visual presente em algumas letras de músicas que indica uma continuidade visual em relação ao restante do livro. A seção dedicada às letras de música segue uma pequena parte do livro Percussões da Pedra Q Ronca -, dedicada a poemas em que a exploração sonora das palavras se torna um dos principais elementos de significação. É possível traçar, assim, no livro, um movimento de aproximação à musicalidade, do poema sonoro à letra de música, em que Percussões da Pedra Q Ronca ajuda a criar a atmosfera musical que se realiza em Uma dúzia e meia de canções e mais uma de quebra.

O título dessa seção veicula uma noção de incompletude, já que não se apresenta a totalidade das letras que ele escreveu, mas apenas uma seleção - o que é evocado ainda pelos termos "meia" e "quebra" -; incompletude que visualmente se realiza pelas quebras de linha entre as palavras, diminuindo o ritmo da leitura, marcando pausas entre as linhas. A pauta que serve de fundo para o título é também significativa ao fazer 
visível a imagética da música - ainda que esteja preenchida apenas por algumas letras, reforçando a falta da contraparte musical da canção no livro. Tais referências à ausência da música, indicadas pela disposição visual da página, demonstram que a transposição da canção para o livro é sempre marcada por uma falta, a qual os aspectos visuais da letra de música procuram suprir.

Para melhor compreender a noção de falta aqui empregada, é necessário retomar a tipologia de processos intermidiáticos de Irina Rajewsky (2012). Para a autora, a canção seria classificada enquanto uma "combinação de mídias", relação intermidiática descrita da seguinte maneira:

\begin{abstract}
A qualidade intermidiática dessa categoria é determinada pela constelação midiática que constitui um determinado produto de mídia, isto é, o resultado ou o próprio processo de combinar, pelo menos, duas mídias convencionalmente distintas ou, mais exatamente, duas formas midiáticas de articulação. Cada uma dessas formas midiáticas de articulação está em sua própria materialidade e contribui, de maneira específica, para a constituição e significado do produto (RAJEWSKY, 2012, p. 24).
\end{abstract}

Tendo em vista essa definição, pode-se afirmar que a canção é uma combinação de mídias, composta tanto pelo texto verbal quanto pela música. Assim, ao transpor as canções para o livro, a contraparte musical se perde, efeito que é evidenciado pelo título da seção. É interessante notar, nesse sentido, a escolha de título da seção, já que, ao usar "canções" ao invés de "letras de música", Waly Salomão parece indicar que está realizando um processo de "transposição midiática", ou seja, "a transformação de um determinado produto de mídia [um texto, um filme etc.] ou de seu substrato em outra mídia" (RAJEWSKY, 2012, p. 24). No caso das canções presentes em Gigolô de Bibelôs, o processo de transposição da canção para a mídia verbal impressa é marcado pela valorização da visualidade, em especial nas relações visuais presentes nos dípticos da seção - ou seja, na valorização do aspecto visual do livro, que apresenta sempre duas páginas ao mesmo tempo quando aberto.

Tendo isso em vista, o uso do díptico se mostra especialmente importante nessa seção ao promover o movimento de aproximação e refração seja de elementos textuais presentes nas letras ou de características visuais das duas páginas. O díptico da página 152 e 153, por exemplo, explora essa tentativa de "compensação visual": as duas letras apresentadas, Luz do Sol e Mal Secreto, são composições de Waly Salomão 
interpretadas por Gal Costa no espetáculo Gal a Todo Vapor, de 1971, marcando o início de sua produção enquanto letrista. Além da proximidade temporal de ambas as letras, a clivagem do díptico apresenta um distanciamento tipográfico evidente em que Luz do Sol se apresenta toda em caixa alta, enquanto em Mal Secreto predominam as minúsculas. Trata-se de uma relação que espelha tanto a diferença de execução de ambas as canções quanto a imagem do eu lírico ali presente. Luz do Sol é interpretada por Gal de modo agressivo, demonstrando a insatisfação do sujeito apresentado pela letra, que se dirige ao personagem com quem tem um envolvimento amoroso marcado pelo desencontro: "QUANDO ESTIVER ASSIM / NÃO ME APAREÇA / SAIA / DESAPAREÇA [...] / DA MINHA VISTA” (SALOMÃO, 1983, p. 152). Por outro lado, em Mal Secreto, a música se constrói nos primeiros versos de maneira intimista, mais próxima do Blues - contrastando com o Rock de Luz do Sol-, o que convém com o "tom menor" da caracterização do eu lírico: "Não choro / meu segredo é que sou rapaz esforçado / fico parado calado quiet o/ não corro não choro não converso" (SALOMÃO, 1983, p. 153). A apresentação em díptico, portanto, de duas canções que, apesar de comporem o mesmo espetáculo e o mesmo álbum de Gal Costa, diferem com relação à performance musical e à caracterização do eu lírico, é evidenciada pelo diferente uso da tipografia nas páginas. Cabe, ainda, notar que o próprio título de Luz do Sol, em que "Luz" aparece em negrito enquanto "Sol" é marcado pelo itálico, demonstra o contratempo representado pelo casal na letra, evidenciado pelo intertexto com o samba de carnaval O Sol e a Vida, de José Roy, Ciro de Souza e Carlos Marques, interpretada por Orlando Silva, em 1964: "EU SOU O SOL / ELA É A LUA / QUANDO CHEGO EM CASA / ELA JÁ FOI PRA RUA” (SALOMÃO, 1983, p. 152).

Outro díptico que chama a atenção na seção de letras de música de Gigolô de Bibelôs é o das páginas 160 e 161, em que ambas as letras ressaltam o delírio e o prazer: Tarasca Guidon e Negra Melodia. Do lado esquerdo, Tarasca Guidon, a única que conta com composição de letra e música de Waly Salomão, cujo título cifrado indica a atmosfera experimental dessa canção, que mistura, na interpretação de Os Doces Bárbaros, os atabaques do candomblé a efeitos psicodélicos do teclado. Os primeiros versos da letra dão o tom de alucinação, em que a "piração" é ressaltada pelas assonâncias em "i" e "u" e as aliterações de "p" e "t": "Piiiii / Pira tudo quanto é pitu / Quando eu em Pituaçu pintar” (SALOMÃO, 1983, p. 160). Com relação à visualidade, 
a letra de Tarasca Guidon deixa em muito a desejar se comparada às experimentações vocais presentes na musicalização de Caetano Veloso, Gilberto Gil, Gal Costa e Maria Bethânia no álbum Doces Bárbaros. Diferentemente da interpretação do grupo baiano, que é repleta de inovações no campo vocal e melódico, o texto apresentado em Gigolô de Bibelôs não se vale de nenhum recurso visual que evoque a atmosfera experimental da canção.

Por outro lado, Negra Melodia explora visualmente a noção de delírio a partir, primeiramente, da disposição do texto na página: trata-se da única letra em que o texto se alinha ao centro e não à esquerda, revelando visualmente as diferenças de metro e ritmo entre os versos, que caracterizam o ritmo sincopado da canção, típico dos gêneros musicais de influência africana - Negra Melodia se aproxima em especial dos ritmos caribenhos, como anotado no fim da página. Como todas as canções apresentadas na seção, Negra Melodia apresenta informações sobre a composição logo abaixo da letra; no entanto, aparecem outras informações, como se transcreve abaixo:

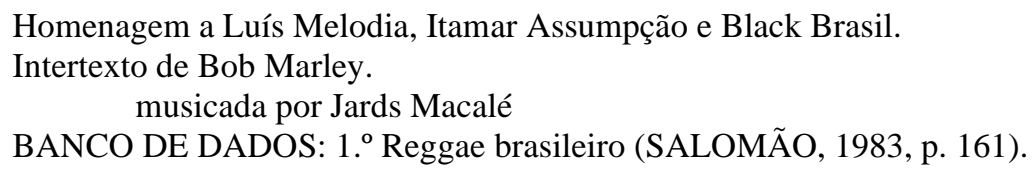

A corrente nota técnica da parceria musical é entremeada de outras informações que localizam a canção na black music, evidenciando a referência a Bob Marley na letra, homenageando músicos negros que gravaram a canção e se apresentando como o primeiro reggae brasileiro. Seguindo a mesma tipografia das demais notas informativas, traçadas em itálico, tais comentários se agregam de maneira irônica às demais informações técnicas presentes em outras letras, buscando se passar como fatos - em especial na delegação da canção enquanto primeiro reggae brasileiro, informação de difícil comprovação histórica. Ainda com relação aos paratextos, a letra de Negra Melodia é a única que apresenta um subtítulo, o que não consta nos créditos nos álbuns em que está presente: "Negra Melodia (Soul Train Domingueira)" (SALOMÃO, 1983, p. 161). Esse subtítulo faz referência ao programa homônimo da televisão estadunidense, que se iniciou na década de 1970 e se caracterizou pelas performances de música e dança da cultura negra. O subtítulo parece indicar que Soul Train, juntamente com o reggae de Bob Marley, foi uma influência na composição, o que é demonstrado 
pela centralidade da dança na letra, que é ainda hoje um dos atrativos mais lembrados do programa. Como apontado por Sandro Ornellas, a musicalidade afro-baiana presente na escrita de Waly Salomão é acompanhada pelo ritmo do corpo, que em Negra Melodia se apresenta a partir da dança:

\begin{abstract}
Baiano, Waly sabe que a música negromestiça de extração africana não é autônoma, mas plasmada a outros meios de comunicação religiosa nos cultos, como os cantos e as danças. Também sabe que a síncope - característica marcante do sistema musical negro-africano - é a ausência no compasso da marcação de um tempo [fraco] repercutindo em um outro tempo [forte], sendo esse espaço vazio preenchido com o corpo, que dá ao tempo vazio a dinâmica e a mobilidade do espaço (ORNELLAS, 2008, p. 132).
\end{abstract}

O corpo que preenche a síncope em Negra Melodia é um corpo de gozo, que afirma o prazer da dança sobre a dificuldade, a tristeza e a doença. É impossível dissociar os problemas mencionados na letra ao racismo, entendido sob uma perspectiva global, compondo uma imagem transnacional do lugar periférico do negro na sociedade: “american black do Brás do Brasil” (SALOMÃO, 1983, p. 161). Ao relevar as mazelas do povo negro através da incitação à dança, a letra transmite uma postura semelhante à de Bob Marley em Three Little Birds ou No Woman, No Cry, canções mencionadas na letra, em que a esperança de um futuro melhor ameniza o sofrimento presente. Na letra de Waly, a dança, ao invés de indicar uma possibilidade de mudança futura, promove o prazer corporal momentâneo, figurando uma forma de escapismo dos problemas sociais e raciais enfrentados. Nesse sentido, a postura hedonista é o que motiva o termo manuscrito que ilustra a canção, disposta na margem da página, em que se lê "overgoze".

Tal neologismo, que utiliza do procedimento de junção de palavras recorrente em sua poética, é formado pela aglutinação das palavras "overdose" e "goze", junção que, ao se aproveitar apenas do prefixo da primeira palavra indica, ainda, no imperativo, um convite à abundância de gozo. O motivo da dança na letra, portanto, se associa tanto ao prazer corporal, expressado pela imagem do gozo, quanto pela vertigem, que a aproximação sonora de "overgoze" com "overdose" revela. Visualmente, a alucinação é remetida pelos círculos concêntricos na letra "o" que marcam um elemento visual recorrente na obra de Waly Salomão, principalmente em seus babilaques. A presença dessa escrita na página parece compensar a falta que acomete a canção ao ser transposta 
para o livro. Se levada em conta a versão original da canção, que surge no álbum Contrastes, de 1977, de Jards Macalé, é possível relacionar aspectos visuais de "overgoze" a escolhas melódicas ou rítmicas ali presentes: nessa versão, Jards Macalé explora de maneira mais evidente a rítmica característica do reggae, em que a repetição incessante do verso "dance" por um coral feminino cria a atmosfera de erotismo e de alucinação. Sobre a repetição, comenta Roland Barthes (1987, p. 56): "a repetição engendraria ela mesma a fruição [juissance]. Os exemplos etnográficos abundam: ritmos obsessivos, músicas encantatórias, litanias, ritos, nembutsu búdico, etc.: repetir até o excesso é entrar na perda, no zero do significado". Visualmente, o sentido de repetição seria associado tanto ao prefixo "over" quanto aos círculos da letra "o", que levariam ao gozo, na segunda metade da palavra.

Ao promover a transposição das letras de música ao livro, Waly Salomão deixa claro não somente o permanente diálogo entre suas diferentes produções artísticas quanto busca alternativas textuais e visuais para suprir a falta da contraparte musical da canção. O trabalho visual da página - em que se destacam o uso crítico das aproximações e afastamentos do díptico e a aparição da caligrafia em "overgoze" demonstra que Waly Salomão é ciente das diferentes características materiais da canção e do poema.

Para Waly Salomão, “a música a que seu texto escrito aspira é a de extração francamente popular" (ORNELLAS, 2008, p. 136) e suas influências residem mais especificamente no cancioneiro nacional. Como já comentado, ele participou ativamente da MPB desde os anos 1970 até seu falecimento em 2003, marcando sua presença na música popular brasileira através de gerações, como as parcerias com Jards Macalé nos anos 1970; as diversas letras de sucesso na voz de Maria Bethânia, que compôs com Caetano Veloso nas décadas de 1970 e 1980; o trabalho, ao lado de Antonio Cicero, com João Bosco no álbum “Zona de Fronteira”, de 1991; e os projetos mais recentes, nos anos 1990 e 2000, com Adriana Calcanhotto e o grupo O Rappa. Apesar de reconhecido sucesso no âmbito da música popular, Waly Salomão comenta, em entrevista cedida em 1998 e retomada no documentário Pan-Cinema Permanente (2008), de Carlos Nader, que a música serve a ele apenas como fonte de renda, sendo a poesia seu verdadeiro objetivo: 
Letra de música, direção de show, produção de disco eu faço para me sustentar, para o leite das crianças, para esse lado monetário. Cada pessoa tem que ter uma forma de ganhar a vida, é a minha forma de levar o pão para a casa. Já a poesia é como se fosse a minha ambição maior, a minha concentração maior de desejo está aplicada à poesia (PAN-CINEMA, 2008).

Semelhante inclinação é observada também no poema Clandestino, do livro Lábia, do mesmo ano da entrevista, na seguinte estrofe:

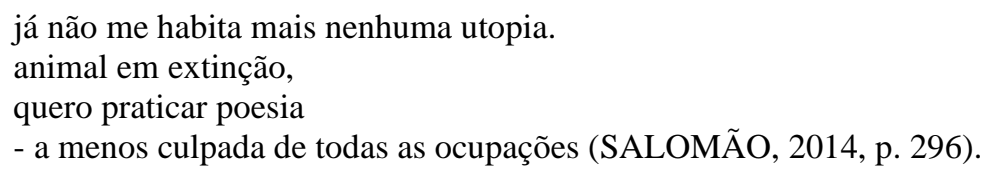

No entanto, em um texto posterior a essa entrevista, Waly revisa tal postura e apresenta outro lado de sua máscara, revelando ser "entranhado" da música popular:

O mercado musical não me sustenta, então outro dia declarei que para a música popular meu coração ficou frio. Mas logo depois percebi o quão entranhado estava o meu ser de música popular, pois não tinha feito mais que uma citação involuntária de um verso de Cartola. Então para rebater um poeta só o salva-vida de outro, T.S. Eliot, quando diz que "todos estes sentimentos inexatos, o granizo e as nevascas das imprecisões verbais... do oceano do som emerge a polifonia" (SALOMÃO, 2005, p. 122).

Como comenta o filho de Waly, Khalid Salomão, no documentário de Carlos Nader, Pan-Cinema Permanente (2008), foi nesse período que Waly Salomão passou por problemas cardíacos e, a partir de então, decidiu voltar suas atenções integralmente à poesia. O que se observa, no entanto, do final dos anos 1990 até sua morte, é que Waly ainda participou de gravações com Adriana Calcanhotto e O Rappa, por exemplo, ao passo que escreveu três livros de poesia - o que, tendo em vista os longos hiatos no começo de sua carreira, indica uma alta produtividade no âmbito editorial. É possível concluir, portanto, que Waly Salomão não deixou de lado a música popular, apesar de ter se empenhado com maior intensidade na publicação de poesia.

Em Gigolô de Bibelôs, a canção é tematizada em diversos momentos, explicitando o contato entre música e poesia na obra de Waly Salomão. Nesse sentido, tendo em vista a teoria de Irina Rajewsky, a relação entre poesia e canção não só pode ser caracterizada por "transposições intermidiáticas" discutidas anteriormente, mas também por "referências intermidiáticas", definidas pela autora da seguinte maneira: 
estratégias de constituição de sentido que contribuem para a significação total do produto: este usa seus próprios meios, seja para se referir a uma obra individual específica produzida em outra mídia, seja para se referir a um sistema midiático específico, ou a outra mídia como sistema. [...]. Em vez de combinar diferentes formas de articulação de mídias, esse produto de mídia tematiza, evoca ou imita elementos ou estruturas de outra mídia, que é convencionalmente percebida como distinta, através do uso de seus próprios meios específicos (RAJEWSKY, 2012, p. 25).

Um dos exemplos de referência intermidiática em Gigolô de Bibelôs se dá na apropriação de Dead Man's Chest no poema Ilha do bizu-besouro. Trata-se da canção que se repete por todo o clássico de Robert Louis Stevenson, Treasure Island, de 1883 a que o próprio título do poema de Waly Salomão alude:

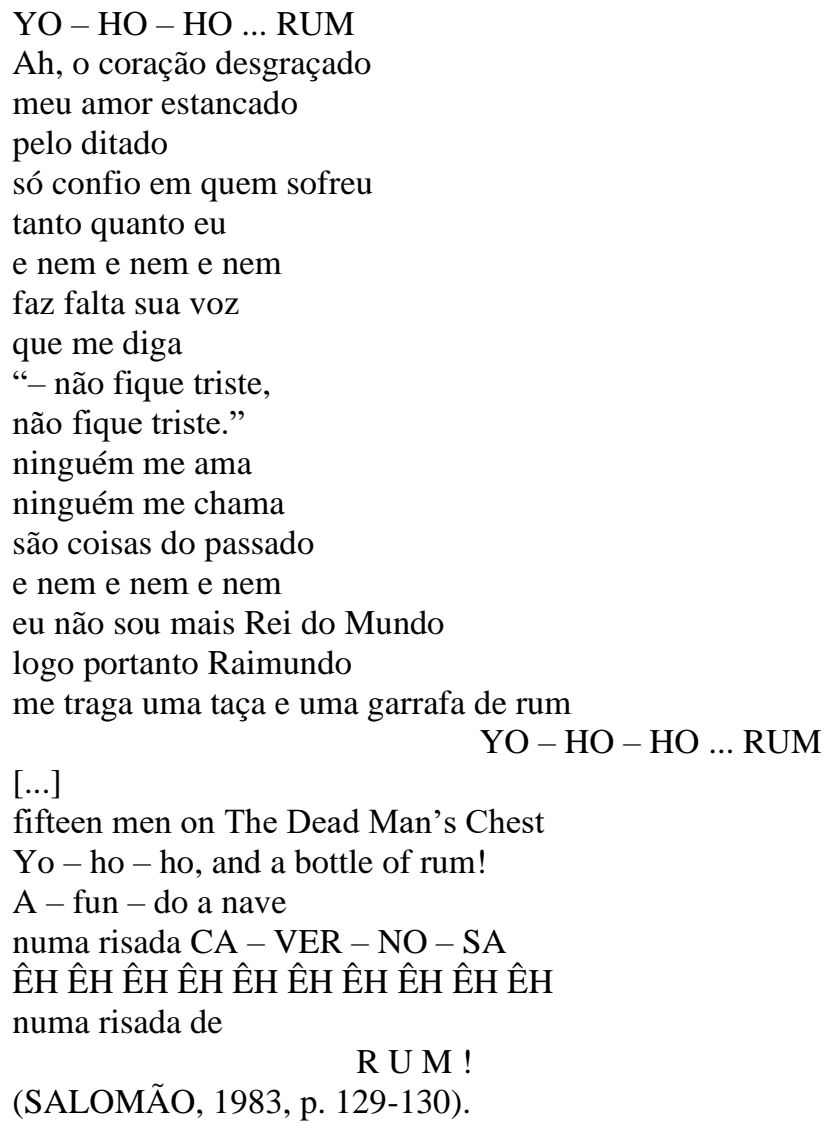

Nesse poema, não só parte da canção presente na obra de Stevenson é retomada, mas ainda são acrescidos elementos do cancioneiro nacional, fazendo do poema uma mescla de temas do romance de aventuras inglês com elementos típicos da música popular brasileira. Há, por exemplo, a apropriação da canção Ninguém me ama, de 
Fernando Lobo e Antonio Maria, cantado por Nora Ney em 1952, consagrada intérprete de samba-canção, gênero marcado pelo sentimentalismo exacerbado - além do óbvio intertexto com a poesia drummondiana com a rima entre "Mundo" e "Raimundo". Ainda com relação à aproximação de Waly com a música popular brasileira, é possível identificar, nesse poema, traços semelhantes aos apresentados nas canções da chamada "linha morbeza romântica", série de composições de Waly Salomão com Jards Macalé, que compuseram, em sua maior parte, o terceiro disco do músico carioca: Aprender a nadar, de 1974. A "morbeza romântica", composta pelo neologismo que aglutina "morbidez" com "beleza", refere-se ao próprio procedimento de pastiche que Waly e Jards empregam com relação às canções afetadas e sentimentalistas da música nacional. Para Lia Duarte Mota, o pastiche da "linha de morbeza romântica" no disco de Jards Macalé se apresenta a partir de dois procedimentos:

\begin{abstract}
em primeiro lugar, reúne novas composições a canções antigas, interligandoas por meio de manipulação de imagens, colagens e bricolagens, no sentido de mesclar fontes distintas, criando algo novo que nada se parece ao original. Em segundo lugar, a interpretação particular, poderia dizer até mesmo afetada, de um exagero que beira ao humorístico, caracteriza o pastiche das canções românticas, da era do rádio, cuja finalidade paródica e estética revela o que seus compositores já haviam anunciado: morbidez e beleza, amor e humor (MOTA, 2012, não paginado).
\end{abstract}

O humor e o exagero são os pontos que mais chamam atenção nessas letras, revelando o sofrimento e o ciúme do eu lírico de modo caricato - como "Dentro da escuridão do quarto / Rasguei no dente seu retrato" (SALOMÃO, 1983, p. 155), em $O$ senhor dos sábados; e "não digo com certeza / mas posso me arruinar / veja / jatos de sangue / espetáculos de beleza" (SALOMÃO, 1983, p. 158), em Rua Real Grandeza. Há, ainda, nas letras da "linha da morbeza romântica", o uso de frases feitas e construções kitsch que evidenciam o caráter cômico dessas releituras da tradição da canção brasileira, como o repetido verso em Anjo exterminado: "me queimo num fogo louco de paixão" (SALOMÃO, 1983, p. 156); e o início de Dona do Castelo, que remete a um sentimentalismo próximo ao da notória composição de Pixinguinha e Otávio de Souza, Rosa: "amor perfeito / amor quase perfeito / amor de perdição que cobre / todo o meu pobre peito pela vida afora" (SALOMÃO, 1983, p. 157). 
No intuito de introduzir tais canções na seção Uma dúzia e meia de canções e mais uma de quebra, Waly Salomão apresenta o texto Mal secreto da linha de morbeza romântica???, em que expõe a motivação por trás de uma dessas composições:

\footnotetext{
Ao escrever SENHOR DOS SÁBADOS, musicada por Jards Macalé, me identifiquei com o amor feminino das santas mulheres especialmente a devota Santa Terezinha suplicante por ser abrasada penetrada pelo amor divino e ser submergida num ardoroso abismo e onde é evidente a analogia entre a linguagem erótica e a linguagem mística. Me tornei SERVA DO SENHOR, naquele tempo once upon a time naquele então da linha de da linha de da LINHA DE MORBEZA ROMÂNTICA.

Hoje: me libertei daquela vida vulgar...

Amanhã: He'll be big and strong.

Assinado: O FAQUIR DA DOR (SALOMÃO, 1983, p. 154).
}

Nesse texto, ao contrário dos comentários anteriores de Mota, que focavam no diálogo das canções da linha de morbeza romântica com o cancioneiro nacional, Waly Salomão comenta a influência dos escritos de Santa Terezinha, provindos da tradição literária e cristã, referência paradigmática do "erotismo sagrado" como teorizado por Georges Bataille (2014, p. 39). É preciso notar, no entanto, que o autor deixa pistas da influência da canção nessas composições, já que a intervocalidade que se apresenta nas canções da linha da morbeza romântica não deixa de aparecer também nessa introdução: Waly Salomão, no final de seu texto, descreve sua relação com o sofrimento que motivou as canções através de citações de Agora só falta você, de Rita Lee e Luís Sérgio Carlini, e The Man I Love, clássico dos irmãos George e Ira Gershwin.

A aproximação entre a obra de Waly Salomão e a musicalidade é, assim, construída a partir do modelo da canção popular. A relação entre poesia e canção que é retomada em sua poética, como apontado neste artigo, integra-se à temática constante em seus poemas da transposição de limites, sendo a imagem mais célebre os versos finais de Câmara de Ecos: "Agora, entre meu ser e o ser alheio / a linha de fronteira se rompeu" (SALOMÃO, 2014, p. 219). Nesse sentido, ao utilizar-se de procedimentos que explicitam as diferenças entre poesia e canção, bem como ao teatralizar uma querela entre tais campos em sua obra, Waly Salomão explicita ao mesmo tempo a fronteira e sua superação. É possível afirmar, por fim, que Waly Salomão, ao realizar a interpenetração dos territórios da literatura e da música popular, evidencia "fenda 
intermidiática" (RAJEWSKY, 2012, p. 28), ou seja, a diferença entre as mídias, ao invés de escamoteá-la através de suas semelhanças.

\section{Referências}

BAHIANA, Ana Maria. Nada será como antes: MPB nos anos 70. Rio de Janeiro: Civilização Brasileira, 1980.

BARTHES, Roland. O prazer do texto. Trad.: Jaime Guinsburg. São Paulo: Perspectiva, 1987.

BATAILLE, Georges. O erotismo. Trad.: Fernando Scheibe. Belo Horizonte: Autêntica, 2014.

COSTA, Nelson Barros da. A produção do discurso lítero-musical brasileiro. 2001. 486f. Tese (Doutorado) - Pontifícia Universidade Católica de São Paulo, Programa de Pós-Graduação em Linguística Aplicada e Estudos da Linguagem, São Paulo. Disponível em: http://www.educadores.diaadia.pr.gov.br/arquivos/File/2010/artigos_teses/LinguaPortug uesa/tese_nelson.PDF. Acesso em: 20 mai. 2021.

MOTA, Lia Duarte. Morbidez e beleza, amor e humor - a estética presente em Aprender a Nadar. Fonogramas, Rio de Janeiro, n. 1, 2012. Disponível em: https://www.maxwell.vrac.puc-rio.br/19441/19441.PDF. Acesso em: 20 mai. 2021.

ORNELLAS, Sandro. Waly Salomão e o teatro do corpo. Ipotesi, Juiz de Fora, v. 12, n. 2, p. 129-143, jul./dez., 2008. Disponível em: https://periodicos.ufjf.br/index.php/ipotesi/\%20article/view/32765. Acesso em: 20 mai. 2021.

PAN-CINEMA permanente. Direção: Carlos Nader. [S. 1.]: Já Filmes, 2008.

RAJEWSKY, I. O. 'Intermidialidade, intertextualidade e 'remediação': uma perspectiva literária sobre a intermidialidade". In: DINIZ, T. F. N. (Org.). Intermidialidade $e$ estudos interartes: desafios da arte contemporânea. Belo Horizonte: Editora UFMG, 2012. p. 15-45.

SALOMÃO, Waly. Armarinho de miudezas. Ed. rev. e ampl. Rio de Janeiro: Rocco, 2005.

SALOMÃO, Waly. Gigolô de Bibelôs. São Paulo: Brasiliense, 1983.

SALOMÃO, Waly. Poesia total. São Paulo: Companhia das Letras, 2014. 
Da canção ao livro: procedimentos de transposição e referência em Gigolô de Bibelôs, de Waly Salomão

Recebido em: 25/05/2021

Aceito em: 29/06/2021

${ }^{1}$ Este artigo é uma atualização de parte da dissertação de mestrado do autor, não publicada e defendida em 2017.

${ }^{2}$ Agradeço ao revisor do artigo que corrigiu a referência à canção de Orlando Silva. 